\title{
Sarcomatoid variant of urothelial carcinoma: Cytological analysis of three cases
}

\author{
NAMIE ARITA*, MITSUAKI ISHIDA*, KEIKO YOSHIDA, AKIKO KAGOTANI, \\ NOZOMI IWAMOTO, MUNEO IWAI and HIDETOSHI OKABE
}

Division of Diagnostic Pathology and Department of Clinical Laboratory Medicine, Shiga University of Medical Science, Shiga 520-2192, Japan

Received August 6, 2012; Accepted October 12, 2012

DOI: $10.3892 / \mathrm{ol} .2012 .990$

\begin{abstract}
Sarcomatoid variant of urothelial carcinoma (SV-UC) is characterized by the presence of biphasic malignant neoplastic components exhibiting morphological and/or immunohistochemical evidence of epithelial and mesenchymal differentiation. SV-UC is a rare variant of UC and the cytological features of this tumor have not been well described. In the present study, we analyzed the cytological features of a series of SV-UC cases; 6 voided urine specimens from 3 patients with SV-UC were reviewed. Several characteristic cytological features were revealed: i) tumor cells were abundant in a necrotic background and while single tumor cells were predominant, small clusters of cells were occasionally present; ii) tumor cells were large-sized and round to polygonal in shape with ill-defined cell borders; iii) tumor cells had a high nuclear/cytoplasmic ratio and enlarged round to oval nuclei containing coarse chromatin and occasional nucleoli; and iv) spindle-shaped atypical cells were rarely identified (1/6 specimens). The cytological features of i), ii) and iii) are indistinguishable from those of conventional invasive high-grade UC. We hypothesize that these tumor cells originated from the conventional high-grade UC component of SV-UC as this component is usually present in this type of lesion, particularly on the surface of the tumor. Moreover, the sarcomatoid component of SV-UC is usually present in the deeper portion of the tumor and therefore detection of this component in the voided cytological specimen is low. Although cytodiagnosis of SV-UC is extremely difficult, cytodiagnosis of malignancy may prove possible due to the presence of a conventional UC component.
\end{abstract}

Correspondence to: Dr Mitsuaki Ishida, Department of Clinical Laboratory Medicine and Division of Diagnostic Pathology, Shiga University of Medical Science, Tsukinowa-cho, Seta, Otsu, Shiga 520-2192, Japan

E-mail:mitsuaki@belle.shiga-med.ac.jp

* Contributed equally

Key words: urothelial carcinoma, sarcomatoid variant, urine cytology

\section{Introduction}

Sarcomatoid variant of urothelial carcinoma (SV-UC) is a rare variant of UC accounting for approximately $0.3 \%$ of all bladder malignancies (1). SV-UC is characterized by the presence of biphasic malignant neoplastic components exhibiting morphological and/or immunohistochemical evidence of epithelial and mesenchymal differentiation (2). The malignant mesenchymal component of SV-UC is usually composed of undifferentiated high-grade spindle cell neoplasm often resembling 'malignant fibrous histiocytoma', with the presence or absence of heterologous elements, including osteosarcoma, chondrosarcoma, rhabdomyosarcoma and liposarcoma (2). The sarcomatoid areas may merge with foci of overlying urothelial carcinoma in situ or conventional invasive UC.

The cytological features of SV-UC are not well known and only one cytological analysis of SV-UC has been previously reported (3). The present case study includes the first analysis of cytological features from a series of SV-UC cases and discusses possible differential diagnostic considerations. This study was approved by the Ethics Committee of Shiga University of Medical Science. Informed consent was obtained from the patients.

\section{Patients and methods}

\section{Case reports}

Case 1. A 64-year-old Japanese male presented with gross hematuria. Cystoscopy revealed multiple polypoid masses with ulceration in the bladder. Biopsies from these polypoid masses and subsequent total cystourethrectomy were performed. Following surgery, chemotherapy was administered. No recurrence or metastases were observed 6 months following surgery.

Case 2. An 80-year-old Japanese male presented with gross hematuria. Cystoscopy revealed a pedunculated papillary tumor in the bladder and tumor resection using a cystoscopy was performed. Two months following the initial procedure, second-look cystoscopy identified no residual tumor. No recurrence or metastases were observed 8 months following the initial cystoscopy.

Case 3. A 75-year-old Japanese male presented with persistent lower abdominal pain. Computed tomography 
Table I. Cytological features of the sarcomatoid variant of urothelial carcinoma.

\begin{tabular}{|c|c|c|c|c|c|c|c|}
\hline Case & Background & $\begin{array}{c}\text { Number of } \\
\text { neoplastic cells }\end{array}$ & $\begin{array}{l}\text { Cellular } \\
\text { arrangement }\end{array}$ & Cell size & Cell shape & Nuclear features & $\begin{array}{l}\text { Spindle-shaped } \\
\text { atypical cells }\end{array}$ \\
\hline 1 & Necrotic & Abundant & $\begin{array}{l}\text { Single } \\
>>\text { small cluster }\end{array}$ & Large & $\begin{array}{l}\text { Round } \\
\text { to polygonal }\end{array}$ & $\begin{array}{l}\text { Large round to oval } \\
\text { with coarse chromatin } \\
\text { and occasional } \\
\text { prominent nucleoli. }\end{array}$ & Present \\
\hline 2 & Necrotic & Few & Single & Large & $\begin{array}{l}\text { Round } \\
\text { to polygonal }\end{array}$ & $\begin{array}{l}\text { Large round to oval } \\
\text { with coarse } \\
\text { chromatin and } \\
\text { inconspicuous nucleoli }\end{array}$ & Absent \\
\hline 3 & Necrotic & Abundant & $\begin{array}{l}\text { Single } \\
>\text { small cluster }\end{array}$ & Large & $\begin{array}{l}\text { Round } \\
\text { to polygonal }\end{array}$ & $\begin{array}{l}\text { Large round to oval } \\
\text { with coarse chromatin } \\
\text { and occasional } \\
\text { prominent nucleoli }\end{array}$ & Absent \\
\hline
\end{tabular}

demonstrated multiple tumorous lesions in the liver and hydronephrosis of the left kidney. Cystoscopy revealed an ulcerated polypoid tumor in the bladder and tumor resection using a cystoscopy was performed. A metastatic bladder tumor in the liver was clinically suspected and chemotherapy was administered.

Cytological analysis. Urine specimens from patients diagnosed histopathologically with SV-UC were retrieved. Six urine specimens from three patients were available in this study (two, one and three samples from case 1,2 and 3, respectively). The specimens were voided urine samples obtained prior to surgical procedure or cystoscopy. Cytological specimens were Papanicolaou-stained and analyzed for cytological features, including background, number of neoplastic cells, cellular arrangement, cell size and shape, cellular border and nuclear features.

Histological analysis. Tissues from cystoscopic or surgical resections were fixed by formalin and embedded in paraffin. Tissue sections were stained with hematoxylin and eosin and subjected to immunohistochemistry using an autostainer (XT system Benchmark, Ventana Medical System, Tucson, AZ, USA) according to the manufacturer's instructions.

\section{Results}

Cytological findings. Cytological features of the 3 cases are summarized in Table I.

Case 1. Two cytological specimens revealed abundant single tumor cells and a small number of tumor cell clusters in a necrotic background. Tumor cells were large-sized and round to polygonal in shape with ill-defined cell borders. The cells had a high nuclear/cytoplasmic (N/C) ratio and enlarged round to oval nuclei containing coarse chromatin and occasional prominent nucleoli (Fig. 1A). In addition, a few spindle-shaped atypical cells with enlarged oval nuclei containing coarse chromatin and dense cytoplasm were also observed in one specimen (Fig. 1B).
Case 2. One cytological specimen revealed a small number of single tumor cells, which were large-sized and round to polygonal in shape with ill-defined cell borders, in a necrotic background. The cells had a high N/C ratio and enlarged round to oval nuclei containing coarse chromatin and inconspicuous nucleoli. Tumor cell clusters and atypical spindle cells were not observed.

Case 3. Three cytological specimens revealed abundant single tumor cells and a limited number of small clusters of tumor cells in a necrotic background. Cells were large-sized and round to polygonal in shape with ill-defined cell borders. The cells had a high N/C ratio and enlarged round to oval nuclei containing coarse chromatin and occasional prominent nucleoli. No atypical spindle cells were observed.

Histopathological findings. Clinicopathological and immunohistochemical features of the 3 cases are summarized in Table II.

Case 1. Macroscopically, multiple polypoid lesions composed of proliferating atypical spindle-shaped tumor cells (Fig. 2A), with ulceration were present in the bladder. Tumor cells had hyperchromatic large nuclei with nucleoli and specific spindle-shaped tumor cells were observed to have rich eosinophilic cytoplasms and striation, which were immunohistochemically positive for desmin, indicative of presence of the rhabdomyosarcomatous component (Fig. 2B). The tumor was comprised of $\sim 70 \%$ of the component and the residual area was conventional high-grade UC, which was largely present on the surface of the tumor (Fig. 2A). The tumor had invaded into the deeper portion of the muscular layer of the bladder (pT2b).

Case 2. The papillary tumor was largely composed of conventional invasive high-grade UC. In addition, proliferating spindle-shaped tumor cells with hyperchromatic large nuclei were observed ( $20 \%$ of the tumor). No heterologous component was identified. The tumor had invaded into the muscular layer (>pT2).

Case 3. The polypoid tumor was composed of proliferating atypical spindle-shaped cells containing large nuclei with nucleoli ( $80 \%$ of the tumor). The conventional invasive 
Table II. Clinicopathological and immunohistochemical features of the sarcomatoid variant of urothelial carcinoma.

\begin{tabular}{|c|c|c|c|c|c|c|c|}
\hline \multirow[b]{2}{*}{ Case } & \multirow[b]{2}{*}{$\begin{array}{l}\text { Age/ } \\
\text { Gender }\end{array}$} & \multirow[b]{2}{*}{$\begin{array}{l}\text { Chief } \\
\text { complaint }\end{array}$} & \multirow[b]{2}{*}{$\begin{array}{l}\text { Histopathological } \\
\text { features }\end{array}$} & \multirow[b]{2}{*}{$\begin{array}{c}\text { Heterologous } \\
\text { component }\end{array}$} & \multirow[b]{2}{*}{ Depth } & \multicolumn{2}{|c|}{ Immunohistochemical features } \\
\hline & & & & & & $\begin{array}{c}\text { Sarcomatoid } \\
\text { component }\end{array}$ & $\begin{array}{l}\text { Conventional } \\
\text { UC component }\end{array}$ \\
\hline 1 & $64 / \mathrm{M}$ & $\begin{array}{l}\text { Gross } \\
\text { hematuria }\end{array}$ & $\begin{array}{l}\text { Sarcomatoid component } \\
\text { >> conventional } \\
\text { high-grade UC }\end{array}$ & $\begin{array}{l}\text { Present } \\
\text { (RD) }\end{array}$ & pT2b & $\begin{array}{l}\text { CK (-), VM (+) } \\
\operatorname{desmin}(+, \text { RD) }\end{array}$ & $\begin{array}{l}\mathrm{CK}(+) \\
\mathrm{VM}(-)\end{array}$ \\
\hline 2 & $80 / \mathrm{M}$ & $\begin{array}{l}\text { Gross } \\
\text { hematuria }\end{array}$ & $\begin{array}{l}\text { Conventional } \\
\text { high-grade UC } \\
\text { >>sarcomatoid component }\end{array}$ & Absent & $\geq \mathrm{pT} 2$ & $\mathrm{CK}(-), \mathrm{VM}(+)$ & $\begin{array}{l}\text { CK(+), } \\
\text { VM (-) }\end{array}$ \\
\hline 3 & $75 / \mathrm{M}$ & $\begin{array}{l}\text { Abdominal } \\
\text { pain }\end{array}$ & $\begin{array}{l}\text { Sarcomatoid component } \\
\text { >> conventional } \\
\text { high-grade UC }\end{array}$ & Absent & pT1 & $\mathrm{CK}(-), \mathrm{VM}(+)$ & $\begin{array}{l}\text { CK(+), } \\
\text { VM (-) }\end{array}$ \\
\hline
\end{tabular}

CK, cytokeratin; UC, urothelial carcinoma; RD, rhabdomyosarcoma; VM, vimentin.

A

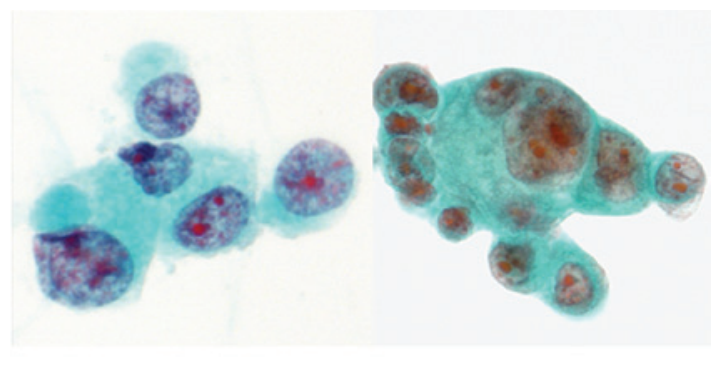

B

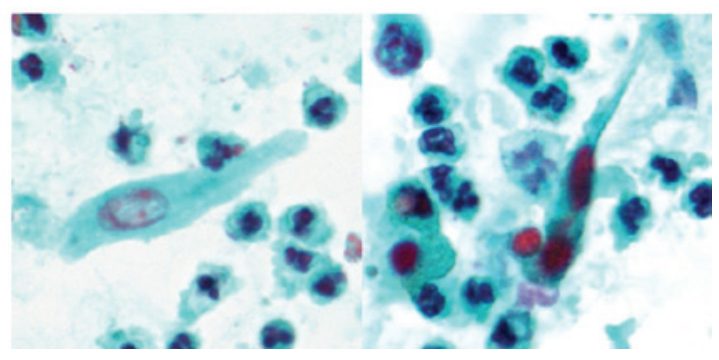

Figure 1. Cytological analysis of the sarcomatoid variant of urothelial carcinoma. (A) Single tumor cells (left) and small clusters of tumor cells (right) with a high nuclear/cytoplasmic ratio and large round to oval nuclei with coarse chromatin and occasional prominent nucleoli. (B) Spindle-shaped atypical cells are also present (Papanicolaou stain; magnification, $\mathrm{x} 400$ ).

high-grade UC component was also identified, largely on the tumor surface. No heterologous component was observed. The tumor had invaded into the subepithelial connective tissue, however, muscular invasion was not observed (pT1).

\section{Discussion}

Cytological examination of urine specimens is important for the detection, diagnosis and follow-up of patients with UC. It is well recognized that cytological examination of urine specimens is highly sensitive for the detection of conventional high-grade UC (4). Moreover, the cytological features of rare histopathological variants of UC, including micropapillary and nested, were previously described (5-8). Although one cytological study of SV-UC has been previously reported (3),

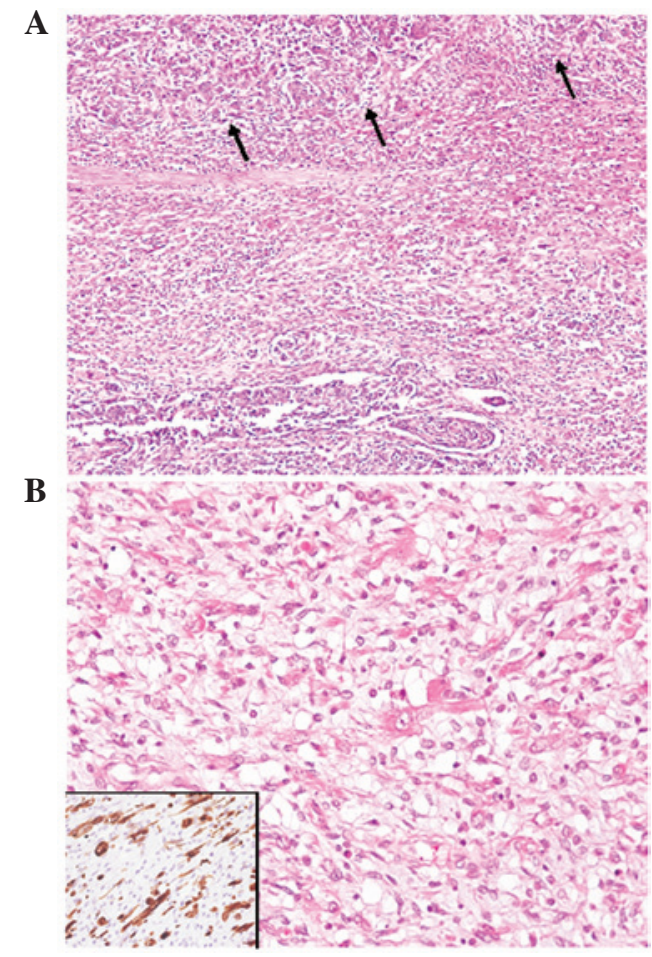

Figure 2. Histopathological and immunohistochemical analysis of the sarcomatoid variant of urothelial carcinoma. (A) Conventional invasive high-grade urothelial carcinoma components (arrows) and sarcomatoid component, which is composed of proliferating atypical spindle-shaped cells (hematoxylin and eosin; magnification, x100). (B) Rhabdomyosarcomatous component (hematoxylin and eosin; x200). Inset, desmin is positive (x200).

the cytological features of a series of SV-UC have yet to be described.

The present study revealed four cytological features of SV-UC: i) Tumor cells were abundant in a necrotic background and single tumor cells were predominant, although small clusters of tumor cells were occasionally present; ii) tumor cells were large-sized and round to polygonal in shape with ill-defined cell borders; iii) tumor cells had a high N/C ratio 
and enlarged round to oval nuclei containing coarse chromatin and occasional nucleoli. iv) Spindle-shaped atypical cells were rarely identified.

Cytological observations in a previous report on SV-UC were consistent with features i), ii) and iii) from the present study (3). However, these cytological features are indistinguishable from those of conventional invasive high-grade UC. We hypothesize that tumor cells with features i), ii) and iii) may have originated from the conventional high-grade UC component of SV-UC, which usually contains conventional invasive UC and UC in situ components, particularly on the tumor surface. These components were present in all cases of this series, although it is unclear whether they were present in the previous report (3). The sarcomatoid component of SV-UC is generally present in the deeper portion of the tumor, therefore, the detection frequency of the sarcomatoid component in the voided cytological specimen may be low, as demonstrated in the present case study, in which spindle-shaped atypical cells representing the sarcomatoid component were observed in only one specimen.

In the present series, 5/6 specimens (cases 1 and 3) were initially diagnosed as malignant (UC) and the remaining specimen (case 2) was suspected to be malignant (suspicious for UC) due to a limited number of atypical cells. However, sarcomatoid component was not reported in any of the cases. The cytodiagnosis of SV-UC may be extremely difficult, however, cytodiagnosis of malignancy may prove possible due to the presence of a conventional UC component.

Cytological differential diagnosis of SV-UC includes UC accompanied by a squamous cell carcinoma (SCC) component and malignant mesenchymal tumors, including leiomyosarcoma and rhabdomyosarcoma. UC is occasionally identified to include a SCC component and pure SCC of the urinary bladder is rare. In voided urine specimens, atypical parakeratotic cells with high N/C ratio and enlarged hyperchromatic nuclei are observed in moderately to poorly differentiated SCC and in well differentiated cases, the presence of squamous cells demonstrating definite malignant features may be rare, although anucleated squamous and atypical parakeratotic cells have been previously observed (9). Spindle-shaped atypical cells are present in the urine specimen of UC with SCC and pure SCC cases, as well as SV-UC $(9,10)$. However, parakeratotic atypical squamous cells are present in UC with SCC and pure SCC cases (10), but not SV-UC, although
SV-UC and UC with SCC contains a conventional high-grade $\mathrm{UC}$ component in urine specimens. These observations may facilitate clinical differentiation of SV-UC from UC with SCC. Leiomyosarcoma and rhabdomyosarcoma must also be included in differential diagnosis of SV-UC as these tumors reveal spindle-shaped tumor cells as well $(11,12)$. However, due to the lack of a conventional high-grade UC component in leiomyosarcoma and rhabdomyosarcoma, differentiation from these tumors is simple and rapid.

\section{References}

1. Torenbeek R, Blomjous CE, de Bruin PC, Newling DW and Meijer CJ: Sarcomatoid carcinoma of the urinary bladder. Clinicopathologic analysis of 18 cases with immunohistochemical and electron microscopic findings. Am J Surg Pathol 18: 241-249, 1994.

2. Lopez-Beltran A, Sauter S, Gasser T, et al: Infiltrating urothelial carcinoma. In: World Health Organization Classification of Tumours. Pathology and Genetics of Tumours of the Urinary System and Male Genital Organs. Eble JN, Sauter G, Epstein JI and Sesterhenn IA (eds). IARC Press, Lyon, pp93-109, 2004.

3. Iwa N, Ito S, Takegaki Y, et al: Cytologic features of sarcomatoid carcinoma of the urinary bladder: a case report. Diagn Cytopathol: Sep 262011 (Epub ahead of print).

4. Brown FM: Urine cytology. It is still the gold standard for screening? Urol Clin North Am 27: 25-37, 2000.

5. Zhu B, Rohan SM and Lin X: Urine cytomorphology of micropapillary urothelial carcinoma. Diagn Cytopathol: May 242012 (Epub ahead of print).

6. Nicolas MM, Jagirdar JS, Arisco AM and Valente PT: Micropapillary carcinoma of the urinary bladder: report of a case and review of its cytologic features. Diagn Cytopathol 39: 784-787, 2011.

7. Sakuma T, Furuta M, Mimura A, Tanigawa N, Takamizu R and Kawano K: Urine cytology of micropapillary carcinoma of the urinary bladder. Diagn Cytopathol 39: 852-856, 2011.

8. Cardillo M, Reuter VE and Lin O: Cytologic features of the nested variant of urothelial carcinoma. A study of seven cases. Cancer Cytopathol 99: 23-27, 2003.

9. Raab SS: Urine cytology. In: Diagnostic Cytopathology. Gray W and Kocjan G (eds). 3rd edition. Churchill Livingstone, Philadelphia, PA, pp398-401, 2010.

10. Owens CL and Ali SZ: Atypical squamous cells in exfoliative urinary cytology: clinicopathologic correlates. Diagn Cytopathol 33: 394-398, 2005.

11. Hemachandran M, Nada R and Rajwanshi A: Leiomyosarcoma of the urinary bladder: a diagnostic challenge in urine cytology. Diagn Cytopathol 31: 281-282, 2004.

12. Mincione GP and Grechi G: Urinary cytology of rhabdomyosarcoma in children. Report of two cases located in the urinary bladder and in the prostate. Pathologica 75: 797-801, 1983. 